\title{
Em nome de quem? Governo, instituições e economia política no campo do combate às doenças respiratórias: o caso da lei antitabaco em Portugal
}

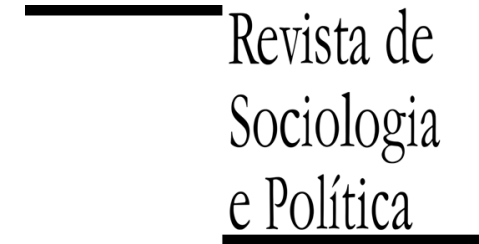

DOI 10.1590/1678-987314225106

\author{
Carlos Barradas
}

\begin{abstract}
RESUMO
O presente artigo defende a tese de que a conjugação de atores e momentos que desencadearam uma nova constelação de instituições nos quadrantes legislativo, executivo e judicial e que levaram à aplicação de um quadro normativo referente ao consumo e venda de tabaco em Portugal, alteraram os discursos sobre direitos e deveres dos indivíduos e, em última instância, os hábitos e crenças enraizadas sobre um aspecto da vida social. A pesquisa foi realizada com recurso a variados materiais legislativos e decorrentes da mídia com ênfase na lei anti-tabaco em Portugal. A pergunta de partida era avaliar de que modo a nova economia institucional e o pragmatismo volitivo constituiriam instrumentos teóricos e metodológicos adequados para a análise e interpretação do percurso da lei anti-tabaco em Portugal. O novo institucionalismo e o pragmatismo volitivo fornecem ferramentas metodológicas e conceptuais úteis para a análise de fenómenos económicos que não podem ser examinados tomando o mercado ou a racionalidade dos indivíduos como únicos referenciais, como em um modelo mecanicista paretiano. Através do recurso aos conceitos de um enquadramento teórico restrito da economia institucional, procurou-se uma caracterização breve dos mesmos, mas aferindo simultaneamente da sua aplicabilidade em um caso empírico que possui o mesmo princípio, em dois países. Confere-se mais consistência teórica aos modelos não dominantes que até agora têm procurado explicar o fenómeno da emergência da lei anti-tabaco e provoca-se novas pistas de investigação que podem ser pertinentes do ponto de vista teórico. Por fim, ressalta-se que aqueles modelos teóricos e metodológicos contêm capacidade explicativa, motivada por sua aplicação noutro contexto empírico.
\end{abstract}

PALAVRAS-CHAVE: lei do tabaco; economia institucional; políticas públicas; governo; pragmatismo volitivo.

Recebido em 28 de Fevereiro de 2013. Aprovado em 8 de Agosto de 2013.

\section{I - Introdução ${ }^{1}$}

\footnotetext{
${ }^{1} \mathrm{O}$ autor deseja agradecer as valiosas contribuições e sugestões dadas pelos pareceristas anônimos da Revista de Sociologia e Política, que enriqueceram este artigo.

2 "Consolidações coletivas de formas de compreender, agir e organizar as interacções em sociedade" (Reis 2009, p. 20). Para uma cartografia do debate institucionalista atual, centrado sobre a noção de instituições, ver Reis (idem) e Hodgson (2009). Para definições de instituiçõos nas quais Daniel Bromley vai basear o seu trabalho - ver Commons (1931) e,
}

s diferentes doenças do foro respiratório e, nomeadamente, as diversas
formas de câncer relacionadas com o tabaco constituem um dos mais
graves problemas de saúde em nível global. Nesse sentido, têm sido desenvolvidas agendas e planos de saúde por vários tipos de instituições ${ }^{2}$, quer em nível estatal e supraestatal, quer em nível da sociedade civil $^{3}$, que pretendem dar resposta à ocorrência dessas doenças. Tais respostas estão geralmente organizadas em torno de campanhas de prevenção ou do seu tratamento, variando a atribuição dos recursos em função, geralmente, das políticas públicas em vigência no momento e que refletem "entendimentos estabelecidos entre os atores que intervêm na esfera pública” ou, como nos diz Reis (2009, p. 129), convenções sociais. Importa, pois, saber como diferentes tipos de instituições respondem a problemas semelhantes e diferenciados, reconhecendo onde cada uma delas deposita suas prioridades e de que modo elas modificam-se ou reestruturam-se para dar resposta a determinados temas. Nesse sentido, a Lei n. 37/2007, de 14 de agosto, a "Lei do Tabaco", prefigurou-se como tema de 
contemporaneamente,

Hodgson (2006)

3 Embora o conceito de

"sociedade civil" seja muito

abrangente e heterogéneo,

conforme retratado por Santos (2003).

${ }^{4}$ Lei n. 37/2007, Diário da

República, $1^{\text {a }}$ série - n. 156 14 de Agosto de 2007.

\section{II - Transição institucional}

\footnotetext{
5 Uma norma é uma "prática herdada da vida quotidiana que constitui muito daquilo que significa ser socializado
}

estudo, buscando-se aferir a relação entre conhecimento e mudança institucional, sendo as políticas públicas uma alteração das regras até então vividas.

A função dessa lei é aprovar "normas para a protecção dos cidadãos da exposição involuntária ao fumo do tabaco e medidas de redução da procura relacionadas com a dependência e a cessação do seu consumo", , agindo preventivamente no que concerne a doenças causadas por aquela substância, quer nos fumantes ativos, quer passivos. Sua aprovação no Parlamento, e consequente implementação, constitui um dos momentos recentes de maior controvérsia no âmbito das políticas públicas em Portugal. Antes e depois de sua implementação, a 1 de Janeiro de 2008, assistiu-se à mobilização de um conjunto de atores que emitiram opiniões diversas sobre o tema e, particularmente, um discurso que abarcava conceitos que gravitavam ao redor daquela nova legislação, como direitos, deveres e obrigações. Partindo-se do papel determinante que essa política assume no combate às doenças respiratórias, pretende-se abordar a própria definição de políticas públicas (definições de políticas de rearranjo das instituições), bem como a noção de instituições e os mecanismos de governação apropriados ao tema. Desse modo, destacar-se-á uma análise que privilegia o questionamento do tipo de instituições chamados a atuar quando no terreno discutem-se políticas públicas diferenciadas. Recorrendo ao quadro teóricoconceptual de autores como José Reis, Warren J. Samuel e Daniel W. Bromley, pretende-se apresentar uma visão neoinstitucionalista sobre as mudanças que ocorrem nesse nível, mas também averiguar o papel do governo (no caso, o português) na (re)definição de interesses sobre uma matéria específica. Crê-se ser possível, assim, contribuir para uma reflexão da teoria económica sobre um domínio que José Reis designa de "difícil apropriação pelo pensamento contemporâneo" (Reis 2009, p. 77) e que simultaneamente envolve o Estado como ator fulcral nas economias contemporâneas, as políticas públicas e decisões coletivas.

O artigo propõe definir os espaços de ação de cada um dos agentes envolvidos na produção de políticas públicas relacionadas ao tabaco, das instituições (ou consolidações) até os indivíduos, tentando identificar a forma como são dadas as respostas a essa questão.

Abordar-se-á também a economia política da prevenção das doenças respiratórias, que pode ser articulada e discutida em três campos distintos: (i) o modelo de combate a essas doenças (sobretudo o câncer), feita através da ação sobre as condições ambientais e sociais que as provocam (nomeadamente políticas públicas baseadas no conhecimento científico - podendo ou não coincidir com a defesa de interesses claros por parte da população), analisando-se igualmente os custos que daqui advêm; (ii) a alteração dos comportamentos e ações que expõem as pessoas ao risco dessas doenças através de uma (re)estruturação dos seus direitos e obrigações, assim como a importância da mudança nas instituições que governam o acesso ao sistema de saúde; (iii) uma forma mais ativista de intervenção na problemática dos problemas respiratórios, nomeadamente através de instituições da sociedade civil, como os movimentos sociais.

Até o dia 14 de Agosto de 2007, não existia em Portugal uma legislação dedicada especificamente ao consumo e venda de tabaco, nas suas mais diversas vertentes. Fumar em locais de trabalho era comum, bem como em múltiplos locais de atendimento ao público. Era uma norma ${ }^{5}$ social, um habitus, e constituía, na perspectiva de Bromley $(2006)^{6}$, um privilégio legal do qual os fumantes gozavam. A ausência de uma política pública específica sobre essa matéria traduzia não mais que o seguinte: existia um determinado arranjo 
dentro de uma cultura particular" (Bromley 2006, p. 51).

${ }^{6}$ As traduções são de responsabilidade do autor (N.R.).

\footnotetext{
${ }^{7}$ Neste sentido, John R. Commons, conhecido institucionalista, falava da mente institucionalizada, ou da personalidade instituída, para justificar o modo como o ser humano se pensa e age dentro de um quadro institucional (Ramstad apud Bromley 2006, p. 49).

${ }^{8}$ Os direitos aqui entendidos enquanto amplificadores do poder do indivíduo sobre os agentes do estado (Bromley 2006, p. 38).
}

\footnotetext{
${ }^{9}$ Embora designemos a economia institucional de um modo uno, é de ressalvar que isso é simplificação teórica elaborada com referência a um conjunto de autores bem demarcada. A economia institucional é muito diversa e possui grande "conflitualidade interna, e a pluralidade epistemológica do institucionalismo é porventura tão grande como a da ciência económica no seu conjunto" (Reis 2009, p. 21).
}

institucional, composto por indivíduos e instituições localizadas algures no passado, que permitia essa prática. E, naturalmente, os/as fumantes, acreditavam ser do seu pleno direito fazê-lo. Tal como, e quiçá paradoxalmente, os/as não-fumantes, que se encontravam numa situação de "não-direito" (ibid.). Nesse âmbito, era tomado por adquirido que quem frequentasse locais onde houvesse fumantes e não desejasse ser prejudicado pelo fumo de outros, teria de abandonar o local, pois não era socialmente concebível que o indivíduo não fumante exigisse ao fumante que parasse com essa atividade em sua presença. Havia portanto um acordo socialmente tácito, não interessando que tal estivesse ou não escrito, mas que social e coletivamente essas regras fossem respeitadas. As "normas e convenções são o não-codificado, embora sejam regularidades geralmente aceites no comportamento que trazem ordem, civilidade e previsibilidade às relações humanas" (idem, p. 51). Isto é, as instituições são algo a que os indivíduos estão habituados em suas vidas diárias e, consequentemente, estes agem enquadrados em uma determinada matriz que, embora libertadora ou constrangedora, é determinante na ação que estes assumem ${ }^{7}$. Do ponto de vista do pragmatismo volitivo, o interesse na escolha deste tema centra-se no fato de que, com grande rapidez, como veremos, os fumantes passaram de uma "situação de privilégio em fumar para uma situação de dever (de não fumar na maioria dos locais públicos)" (idem, p. 156).

Tal sucedeu que, na data anteriormente mencionada, foi aprovada, na Assembleia da República portuguesa, uma lei que abordava precisamente a colocação dessa temática no âmbito legal, executivo e judicial. Existe portanto, desde então, uma legislação que define claramente os direitos ${ }^{8}$, deveres, obrigações, privilégios e atribuições de poder a quem está direta ou indiretamente relacionado com o tabaco. Esse rearranjo do quadro institucional, ou seja, essa nova política pública, em que o governo desempenhou um papel crucial, despertou todo um conjunto de reações por parte de vários agentes e atores da sociedade portuguesa que se manifestaram ora a favor, ora contra a nova lei. Alguns exemplos são, naturalmente e em primeiro lugar, o governo português, e posteriormente outras organizações como a Organização Mundial de Saúde (OMS), Associação da Hotelaria, Restaurante e Similares de Portugal (AHRESP), a Liga Portuguesa Contra o Câncer e a Sociedade Portuguesa de Pneumologia. Mas também individualmente houve reações (algumas delas particularmente críticas) por parte de opinion-makers e indivíduos de outras esferas da sociedade.

Por que a escolha por um quadro teórico decorrente da economia institucional $^{9}$ para a abordagem a esse caso? A escolha da economia institucional como uma lente analítica encerra em si dois fatores preponderantes na área das ciências sociais e, particularmente, na perspectiva da antropologia: assume "o papel [constitutivo] da cultura e a importância dos recursos cognitivos ao mesmo tempo que o do cálculo e da selecção estratégica”, oferecendo assim ferramentas metodológicas para lidar com "problemas que nos aproximam do mundo contemporâneo" (Reis 2009, p. 35) e, por outro lado, concebe a ideia de que os indivíduos criam ativamente instituições para reduzir a incerteza do "processo da vida" (Veblen apud Reis 2009, p. 33), aquelas entendidas como "as regras, rotinas, habitus e convenções que enquadram mentalmente os indivíduos" (Reis 2009, p. 39). Tal é devido ao fato de que o modo como estes se comportam no âmbito de quadros sociais e culturais específicos, a formulação de conceitos como racionalidade, verdade, realidade, são construídos num quadro histórico, social, cultural e conceptual determinado. Revelam assim a sua intencionalidade e tal constitui, portanto, um vetor de análise comum para a antropologia e economia institucional, ou uma economia com roupagem antropológica. 
Por outro lado, coloquemos inicialmente a questão de outro modo: qual o contributo que a economia convencional poderia dar a um contexto de surgimento de uma política pública desse cariz? Pode-se inferir que é mais eficiente (em uma perspectiva de Pareto ou dos economistas da corrente neoclássica) se mais pessoas deixarem de fumar? No que concerne ao Sistema Nacional de Saúde, em particular, onde menos pessoas dariam entrada por doenças relacionadas com o fumo do tabaco, direto ou passivo? Ou essa eficiência poderá ser atingida através da diminuição de novos fumantes e, consequentemente, diminuição de público consumidor do mercado do tabaco? Ou através dos fumantes que passam a não poder frequentar os estabelecimentos de atendimento ao público de cigarro em punho? Ou que os não-fumantes passaram, subitamente, a ter mais poder que os fumantes? Em última análise: os benefícios sociais e privados excedem os custos sociais e privados nessa ação em particular? Dirão os economistas neoclássicos que a legislação previamente existente era ineficiente? E que dirão agora? Houve uma transgressão do óptimo de Pareto? Posto de outro modo: segundo a perspectiva paretiana, essa nova legislação só seria desejável se os seus benefícios excedessem os custos prévios à sua implementação. Se a lei, que de um modo geral serve como "um tónico psíquico face à ambiguidade social e existencial" (idem, p. 12) foi criada, porque tal sucedeu? Terá sido porque o mercado apresentou falhas, não tendo conseguido dar resposta a tudo isso, dado que para a economia neoclássica a "mudança institucional é frequentemente olhada, prima facie, como uma interferência nos alegadamente processos naturais do mercado (ibid.)? Podemos então deduzir, como Bromley afirma, que existe um grande conjunto de circunstâncias nas quais o mercado, como ferramenta analítica para a mudança institucional, já não é apropriado.

Do ponto de vista da economia institucional, essa mudança rápida de um certo tipo de concepção do comportamento dos indivíduos em sociedade sobre um tópico específico gera particular interesse. De resto, Bromley (idem) já abordou o tema da política pública no caso da legislação sobre tabaco nos Estados Unidos da América (EUA) através das lentes pragmatistas, e ao qual voltaremos mais adiante. Para esse autor,

"políticas públicas são ação coletiva que age sobre o constrangimento, libertação e expansão da ação individual. Nesta configuração, vemos que o propósito das políticas públicas é precisamente modificar as instituições económicas. O resultado de políticas públicas é portanto [a criação de] novas (diferentes) instituições económicas. Mais particularmente, as novas instituições económicas redefinem quem deve ou não deve tomar alguma ação específica, quem pode tomar certas ações sem interferência de outros indivíduos, quem pode tomar certas ações com a ajuda explícita do poder coletivo, e quem não pode esperar que o poder coletivo tome certas ações em seu benefício" (idem, p. 23).

Isto é, um arranjo institucional diferente do previamente existente vai, por um lado, libertar alguns indivíduos de certos tipos de comportamento (de outrem, principalmente), mas vai igualmente restringir outros, sendo que o sentido do apoio coletivo (ou seja, o modo como se podem mobilizar argumentos legais, judiciais ou executivos em favor ou contra uma ação individual num determinado contexto - como por exemplo, solicitar o apoio das autoridades quando em um local de "não-fumantes" está alguém a fumar) pode ser totalmente invertido. Nesse quadro, a retórica do "direito a" ganha outra dimensão, dado que, se previamente ao novo arranjo institucional, poderia ser um direito fumar em todos os locais públicos (embora, como veremos, tal não se trate de um direito efetivo, na medida em que não se poderiam mobilizar agentes legais para defender esse mesmo direito. Daí considerar-se uma norma,

${ }^{10}$ Neste sentido, Bromley adverte para a diferenciação no interior do universo das ou um privilégio legal, mais que um direito $)^{10}$, após a aprovação da lei o "direito" fica do lado dos não-fumantes. Reconhecendo o conflito e o poder como elementos centrais na atividade humana (Reis 2009), deveremos igual- 
"correlações legais", separando-as entre "estáticas" e "dinâmicas" e com respetivas implicações para dois indivíduos que se encontram em cada um dos lados das instituições, "alfa" e "beta". No esquema proposto, fica patente a dicotomização e implicações das alterações de poder, pois o conceito de instituição implica sempre dualidade (Bromley 2006, p. 53).

${ }^{11}$ Pois, segundo Bromley (idem, p. 17), os "indivíduos não conseguem mudar a estrutura institucional; apenas a ação coletiva pode alterar os campos de escolha dos indivíduos". Quando se diz acção coletiva, objetiva-se indicar que as novas instituições económicas (não as normas ou convenções, mas novas regras em vigor e novos regimes de atribuição) são produtos dos processos dos governos. Isto é, as instituições económicas recebem forma e conteúdo (e poder) que é dada pelos agentes do Estado a que chamamos governo (idem, $\mathrm{p}$. 35-36).

${ }^{12}$ Tal sucedeu em um comentário feito por Miguel Sousa Tavares na TVI (sigla para Televisão Independente), a 1 de Maio de 2007. mente admitir que as instituições existentes não são justificadas pelas escolhas e ações dos indivíduos que vivem em um determinado momento, mas sim de pessoas e momentos do passado, e é essa descoincidência que leva à razão de ser das políticas públicas. Para estas, portanto, a questão mais pertinente é: levarnos-á um comprometimento (coletivo ${ }^{11}$ ) para com a política pública onde queremos estar no futuro?

Acedamos ao plano empírico para justificar o enquadramento teórico: aquando do conhecimento da aprovação da nova legislação sobre o tabaco, um conhecido opinion-maker nos média portugueses, Miguel Sousa Tavares, criticou duramente essa novidade, indicando que era seu direito, um presumptive right - direito presumido (Bromley 2006, p. 65), fumar onde lhe aprouvesse, e que nem o nazismo-fascismo ${ }^{12}$ tinha levado tão longe medidas restritivas do comportamento individual:

"Com a entrada em vigor da famigerada Lei 37/07 - a lei antitabagismo -, passa a vigorar entre nós uma lei do terror e o país reencontra-se com a sua velha vocação de proibicionismo, delação e repressão dos direitos individuais. [...] Chamada a resolver uma situação em que se tratava de proteger os não-fumantes do fumo passivo, obrigando à criação de áreas específicas para fumantes, o legislador não esteve com meias medidas e quis lá saber se os fumantes tinham ou não alguns direitos também. A regra foi proibir quase sempre e em todo o lado e, quando misericordiosamente entreabriu algumas portas (como no caso dos bares e restaurantes), determinou tamanhas exigências técnicas que a tradicional lei do menor esforço e a falta de profissionalismo em vigor no setor se encarregaram de chegar à solução mais fácil: que vão fumar para a rua e é enquanto podem. [...] A tristeza por viver num país onde se respeita tão pouco a liberdade dos outros". (Tavares 2008).

Como Bromley afirma, ter um direito em relação a uma atividade particular "é ter a capacidade de compelir o estado a proteger os próprios interesses" (Bromley 2006, p. 54). Nesse sentido, a retórica utilizada por Miguel Sousa Tavares era, assim, conceptualmente errada, pois o que os fumantes detinham antes da nova política pública sobre o tabaco era um privilégio legal, dado que, na ausência de um quadro legislativo, não havia mecanismos sancionatórios daquele comportamento em espaços públicos. O Estado não podia, portanto, ser mobilizado através dos seus ramos judiciais, legislativos e parlamentares para uma atuação compulsória sobre qualquer um dos intervenientes, o fumante ou o suposto queixoso. Mais, o que aqui estava em causa "não [era] saber se [existia] ou não governo, mas a quem o governo [estava] a defender interesses" (Samuels 1989 , p. 432) e, nesse caso, eram os fumantes, pois o arranjo institucional assim permitia. Ainda assim, o que sucedeu, parece ter sido baseado no fato de que a mente habituada frequentemente não reconhece as instituições (no sentido em que raramente se constatam) até o momento em que são alteradas, o que revela simultaneamente um ajustamento individual e coletivo, social e cultural, a uma norma existente. Assim,

\footnotetext{
"nosso interesse nas instituições surge porque uma política pública nova é apenas uma nova constelação de instituições formulada nos planos legislativo, executivo e judicial. Porque as novas instituições ao nível nacional, regional ou local representam ação em restrição, libertação ou expansão da ação individual, uma nova lei ou uma nova regra dos ramos legislativos (ou dos tribunais) é apenas uma alteração à ação coletiva anterior (ou mero costume) que agora modifica a extensão dos domínios de escolha dos indivíduos. Alguns serão auxiliados pelas novas regras, e outros serão prejudicados. Aqueles prejudicados pelo novo desenho institucional irão provavelmente lamentar a "interferência" do governo naquilo que julgam ser uma realidade historicamente santificada e portanto justificada. Aqueles anteriormente prejudicados no status quo institucional anterior desfrutarão da nova quietude" (idem, p. 47).
} 
Fernanda Câncio, jornalista, contrapôs-se à argumentação de Miguel Sousa Tavares com ironia, recorrendo a uma analogia com o consumo de drogas lícitas e ilícitas:

\begin{abstract}
"Realmente, não se compreende: como pode uma lei que visa proteger os que não fumam dos que fumam ser mais severa sobre os que prevaricam que uma lei que visa proteger de si próprio quem usa certas substâncias tidas como prejudiciais? Está-se mesmo a ver que o Estado deve ser muito mais brutal com quem faz mal a si próprio do que com quem faz mal aos outros. [...] Afinal, faz tanto sentido equiparar as coimas respeitantes ao uso de drogas ilícitas com as que incidem em quem fume em locais públicos fechados como comparar o que a lei determina para quem beba álcool até cair (nada) e o que prevê para quem, embriagado, conduza um veículo (contra-ordenação, inibição de conduzir ou prisão, conforme o grau de alcoolemia). Num caso, o abuso só prejudica o próprio; no outro, põe terceiros em risco. Se é assim tão óbvio no caso do álcool, devê-lo-ia ser também nos outros. Ou não?" (Câncio 2007).
\end{abstract}

Bem como João Miguel Tavares que, na sua crónica do Diário de Notícias de 8 de Maio de 2007 (Tavares 2007), também critica o cronista e, em uma parábola entre a alusão à lei do ruído e à lei do tabaco, e o modo como processa-se esta altercação legal baseada na tensão direito-liberdade entre os indivíduos com interesses diferentes, intitula sarcasticamente uma crónica de "Calem-me a criancinha que eu não consigo mastigar". Desse modo, podemos traduzir o debate entre esses indivíduos neste sentido:

"A interferência do governo em uma pessoa é a protecção de outra pessoa pelo governo. Constrangimento para Alfa é libertação para Beta. [...] Posto de outro modo, quando o direito, privilégio, poder ou imunidade de determinados agentes económicos é colocado em causa por queixas de cidadãos e ação política, rapidamente o governo se torna o inimigo. E a conversa vira-se invariavelmente para uma perda de "liberdade"” (Bromley 2006, p. 65).

Assim que:

"Quando Alfa e Beta estão no mesmo campo de ação ou conflito, para que o governo proteja os interesses de Alfa como propriedade (ou como um direito per se) o governo está a negar protecção aos interesses de Beta, expondo Beta às consequências do fato de Alfa ter o direito. Os direitos possuem esta natureza dúplice; para mais, as externalidades têm um caráter recíproco relacionado. Para cada interesse protegido (direito) existe um outro no mesmo campo de ação que não está protegido, mas exposto" (Samuels 1989, p. 430).

As instituições atuais são portanto o reflexo de propósitos, valores, agendas políticas e económicas anteriores. As instituições existentes não são justificadas pelas escolhas e ações dos indivíduos que vivem nesse momento. Quando o governo interfere nos campos de ação dos indivíduos (ou seja, quando se dá uma mudança da arquitetura institucional), estes falam frequentemente da perda de direitos, quando conceptualmente essa acusação possui falhas de base. Fica igualmente patente que o caso da lei do tabaco, ao revolver no terreno da tensão entre direitos e deveres, liberdades e privilégios, demonstrou ser um óptimo exemplo para revelar o modo como os ramos legislativos e judiciais das instituições são determinantes na avaliação e julgamento dos comportamentos dos indivíduos. Se tal aconteceu, é porque o quadro da economia institucional selecionado oferece condições teóricas e analíticas propícias para o estudo deste tema, ao contrário da economia neoclássica, baseada no mercado como única ferramenta analítica, e esperando a racionalidade como estado e condição sine qua non dos indivíduos nos processos de tomada de decisão. Seguidamente, aplicar-se-á o quadro teórico à própria razão da mudança institucional. 
III - Por que a mudança?

A importância das mudanças institucionais decorre do fato de traduzirem o momento em que se erguem novas crenças sobre um determinado tema. E naturalmente, se tal sucede, é porque se imaginou um mundo melhor (se não necessariamente melhor, diferente) com outra configuração institucional. Assim, nesse caso, pode-se afirmar a existência de uma premissa volitiva, uma "proposição respeitante ao fim [ou consequência] de uma ação" que visava a diminuição de consumidores de tabaco e das doenças com este relacionadas. Para tal, a ação, a nova política pública, teve de ser tomada naquele momento. Daniel Bromley explica que essa atitude, designada de volição prospetiva é, portanto, a "vontade humana em ação, virada para o futuro, contemplando as maneiras no qual o futuro pode-se e deve concretizar-se" (Bromley 2006, p. 15).

Assim, no primeiro artigo do Capítulo $1^{\circ}$, nas Disposições Gerais da legislação aprovada, consta que "A presente lei dá execução ao disposto na Convenção Quadro da Organização Mundial de Saúde para o Controlo do Tabaco, de 8 de Novembro", remetendo assim a dois pontos importantes: em primeiro lugar, a forte influência de uma organização supranacional na elaboração e implementação dessa lei e, em segundo lugar, o fato de o Estado português ter sido signatário dessa mesma convenção. Considerando o papel do Estado nessa mudança de política pública, tal vai contra a ideia veiculada por algumas correntes da economia que sustentam o progressivo enfraquecimento do Estado no contexto dos diversos movimentos económicos atuais, intensos e turbulentos. José Reis discorda dessa visão, sugerindo que "o Estado é hoje, nas economias contemporâneas sujeitas a intensos processos de mudança, um objeto analítico importante e uma arena central da vida socioeconómica". Do mesmo modo, este "não é apenas o governo e os seus funcionários, são múltiplas agências e institutos" (Reis 2008, p. 76). Essa definição, englobando portanto o governo, obriga a um esclarecimento conceptual que importa avançar: a distinção entre governo e Estado, se bem que ambos partilhem um elemento, a sua importância na organização e mobilidade económica. Warren J. Samuels argumenta que um

“governo participa na organização e controlo e, portanto, na contínua construção e reconstrução da economia [...] [e] protege seletivamente, como direitos, certos interesses e não outros - e são os direitos que formam, estruturam e operam através do mercado e da economia" (Samuels 1989, p. 428).

Ambos os autores assumem portanto "um pressuposto geral contrário a muitas ideias correntes, segundo as quais o Estado-Nação [e seus governos] sofre[m] um profundo e irrecuperável declínio" (Reis 2009, p. 77), caraterizando-o como "um conjunto de instituições, redes, procedimentos, modos de cálculo e normas e também os respetivos tipos de comportamento estratégico" (idem, p. 84).

O Estado e, mais particularmente, o governo e a sua nova política pública, foram o alvo da crítica de Vasco Pulido Valente, ensaísta, escritor e comentador político. Antagonista da adopção da lei do tabaco, foi igualmente corrosivo para com o Ministro da Saúde do governo socialista de então, argumentando que:

"O Sr. ministro da Saúde, Correia de Campos, tem sido até agora um bom ministro: inteligente, informado, reformador. Mas com certeza que lhe passou pela cabeça uma coisa má. Não havia um movimento, uma exigência popular, nem se quer a pressão de um interesse qualquer, quando de repente, da apatia do país, da conformidade geral, do nada, o Sr. ministro resolveu tirar do chapéu uma nova lei contra o tabaco. Toda a gente compreende porquê. O exemplo da América e da "Europa" (a Itália, a Irlanda, a Espanha) brilhava ao fundo do túnel e o Sr. ministro não resistiu. Também ele não quis cometer o terrível pecado do atraso e, ainda por cima, se o que se pedia dele não passava de um pequeno ato de 
${ }_{13}$ Apesar da pesquisa empírica efetuada, não foram encontradas, até à data, referências a movimentos ou associações que tivessem feito algum tipo de pressão para a criação ou adopção de tal lei.

${ }^{14}$ Em outras áreas científicas, como a antropologia médica, o conceito de crença e sua produção é central para o entendimento de fenómenos de índole social e cultural em diferentes grupos. Vide Good (1994). prepotência, com publicidade assegurada e, para o Estado, praticamente gratuito". (Valente 2006).

O governo como inimigo, portanto, interferindo nos "mecanismos naturais do mercado" (Bromley 2006, p. 18). Sendo verdade que, pela pesquisa efetuada, não surgiram dados relevantes que desmintam a noção de que efetivamente não havia movimentos ou exigências populares a favor da implementação dessa ou semelhante 1 i $i^{13}$, há um outro elemento que fica claro nas palavras do colunista, a metáfora do exemplo do "avanço" da América e da Europa. Não será ideia peregrina indicar que o enquadramento institucional de Portugal em um âmbito mais alargado de países terá influenciado (única e decisivamente, acredito) a criação e adopção dessa legislação, pois "as dinâmicas das sociedades e das economias estão fortemente enquadradas por ambientes institucionais que as influenciam e determinam, e esses contextos são tão poderosos como diversos" (Reis 2009, p. 47), pese embora a sua "ordem constitucional" própria (idem, p. 132). Emerge, pois, a possibilidade de afirmar que, no contexto português, não foi o papel da ciência (pelo menos de maneira direta) ou de movimentos de cidadãos ou judiciais que motivaram a mudança institucional, mas sim essa dialética com um panorama institucional mais abrangente. Por outro lado, interessa salientar que não é só devido a essa envolvência institucional que a nova política pública foi determinada. Efetivamente, se tal aconteceu, foi porque, da mesma maneira, o governo/Estado acreditava que esse novo arranjo seria benéfico para os objetivos propostos. Apesar de ser crucial averiguar os processos através dos quais os indivíduos vêm a crer em algo como sendo "verdade", a problemática da crença, ou da produção de crença, é central no âmbito do pragmatismo volitivo ${ }^{14}$.

Será portanto possível afirmar que, de acordo com o peso que o Estado desempenha e contrário às correntes que o dão como morto, o Estado, a instituição-das-instituições (idem, p. 83) (como signatário de uma convenção, e pertencendo a um enquadramento institucional mais abrangente) e, mais particularmente, o governo socialista (por ser aquele que estava no poder quando foi implantada a nova política pública) foi o ator essencial (se não mesmo o único) que desencadeou esse processo. Aliás, segundo Daniel Bromley, é nos discursos dos parlamentos que as discussões sobre essas opções são tomadas, e é para isso mesmo que servem esses ramos dos governos. O processo político trouxe, assim, uma visão sobre o futuro, no sentido em que havia um resultado desejado, e para que esse resultado fosse atingido, teria de ser tomada uma decisão sobre política pública. A perspectiva futura de uma diminuição das doenças relacionadas com o tabaco foi razão suficiente (Bromley 2006) para a criação e adoção dessa lei. Assiste-se portanto a uma quase inevitabilidade da presença e ação do Estado sobre a sociedade portuguesa, e José Reis aponta para uma justificação, ao afirmar que

"A centralidade do Estado na economia portuguesa é grande porque é grande o seu papel na estruturação dos comportamentos dos atores sociais e das relações que estes estabelecem. De fato, os intervenientes no processo económico colocam-se numa grande dependência dos papéis que o Estado assume para estabelecer contextos de ação, fixar significados, estabelecer consensos" (Reis 2009, p. 156).

Uma ressalva deverá ser feita, no entanto: quando se refere o papel fundamental do Estado, é necessário indicar que este não é uma unidade homogénea e coerente, nem no espaço nem no tempo. As formas e retóricas que este vai assumindo vão-se modificando em função das ideologias em vigor e dos enquadramentos económicos e institucionais que o rodeiam. Contudo, o Estado assume forte centralidade na "institucionalização e resolução dos conflitos, no relacionamento entre os atores económicos e sociais" (Reis 2009, p. 88), e é um 
${ }^{15}$ Sobre o uso da justiça por parte de movimentos sociais e, em particular, o movimento ambientalista, veja-se Duarte (2011).

\section{IV - As lentes pragmatistas}

elemento "central da regulação económica, como é indispensável para que se assegure a coerência do sistema económico e da vida social” (idem, p. 90).

Um aspecto que resta ainda focar é a mobilização judicial motivada para, ou motivada por, essa nova lei. A ativação dessa vertente, em particular a mobilização dos tribunais por alguns tipos de movimentos sociais, não é frequente em Portugal, e a que existe dá-se principalmente através do movimento ambientalista ${ }^{15}$. No entanto, sobre a temática abordada neste artigo, não há conhecimento de qualquer movimentação. Mais, para ilustrar essa escassez, apenas em um momento foram mobilizados argumentos do foro judicial, e para contrapor a lei do tabaco, sustentando a situação de economicamente lesados. A AHRESP fê-lo, interpondo uma providência cautelar pretendendo suspender alguns dos artigos do diploma, nomeadamente aquele que diz respeito aos extratores de fumo que os restaurantes que optem por serem espaços para fumantes teriam de instalar. Esta acabou por ser rejeitada, mas reflete o parco investimento dos indivíduos e dos grupos no uso dos tribunais (ou seja, de um uso institucional) para atingir determinados fins. Poderá tal estar relacionado com a ideia de que "as instituições só são restrições aos grupos e indivíduos, mas tal seria 'manter o status quo do "mercado"," (Bromley, 2006, p. 32).

\begin{abstract}
"O governo é, contrariamente às ideologias que desejam de outro modo, bastante fundamental no que respeita à natureza, estrutura, operação, e resultados obtidos do sistema económico, inclusivamente num sistema económico nominalmente considerado como "mercado"” (Samuels 1989, p. 429).
\end{abstract}

Feito o enquadramento, através da economia institucional, da implementação da lei do tabaco em Portugal, importa agora, do modo que Daniel Bromley fez relativamente ao fenómeno no contexto americano, aplicar o filtro do pragmatismo volitivo no caso português, e verificar a (in)comensurabilidade existente. Segundo esse autor, o pragmatismo volitivo está "prioritariamente focado na explicação da ação individual e coletiva e que possua resultados económicos" (Bromley 2006, p. 155) e baseia-se na seguinte premissa:

\begin{abstract}
"Levar-nos-á um compromisso tomado com a presente estrutura institucional onde queremos estar no futuro? Se a resposta a essa questão não for promissora, então existe a necessidade de um novo arranjo institucional. Este processo é informado pelo conceito de causa final - o propósito a ser servido num novo arranjo institucional. O resultado provável (e desejado) justifica (é a razão para) a ação coletiva que é a causa da mudança institucional que irá plausivelmente originar o resultado desejado. Podemos assim dizer, portanto, que o resultado plausível fornece provas de razão suficiente para o novo arranjo institucional" (idem, p. 13).
\end{abstract}

A premissa epistémica deste "estilo de pensamento" (Fleck 1986, p. 66), baseada em crenças científicas e tradicionais (Bromley 2006, p. 15), seria a de que se as pessoas fumassem menos haveria menos doenças do foro pneumológico (e particularmente oncológicas) motivadas pelo fumo do tabaco e pela quantidade de fumantes. Essa premissa é, simultaneamente, uma previsão e uma prescrição, na medida em que leva à mudança de um desenho institucional, criando um novo. A "premissa epistémica prescreve o que deve ser feito para que um resultado desejado seja atingido. E a premissa epistémica prevê que um resultado desejado será atingido se uma ação particular for tomada" (ibid.). Uma escolha que reflita a premissa epistémica leva, assim, à premissa volitiva, que indica o que "deve" ser feito: "nos estados democráticos, estas declarações do que deve ser (ou devia ser) feito emanam dos ramos judicial e parlamentar do governo. Essa é, afinal, a razão por que estes ramos existem" (idem, p. 16). 
O forte componente cultural e cognitivo que Bromley veicula nesse "estilo de pensamento" (Fleck 1986, p. 66) encontra-se fortemente vinculado a uma crítica aos valores do objetivismo, da racionalidade e do realismo difundidos pela modernidade. Tal escolha deve-se ao fato de que os discursos decorrentes da economia neoclássica como eficiência, optimização e potenciais melhoramentos do óptimo de Pareto são parte constituinte e fundamental do projeto modernista (Bromley 2006). Através do desafio pragmatista, procura-se oferecer uma visão epistemológica e aproximação (uma teoria de ação) que se coloca em claro contraste com a tríade modernista, propondo uma outra, olvidada, e que é marcada pelo relativismo, pela irracionalidade e antirrealismo (idem, p. 20). A diversidade epistemológica é, aliás, um dos pontos fundamentais da corrente pragmatista da economia, que assume a possibilidade de uma pluralidade de construções epistemológicas e conceptuais (diferentes cosmovisões e constelações de sentido), procurando a sua articulação, e simultaneamente negando a existência de um eixo central em torno do qual se erigiriam as diferentes racionalidades. Para Bromley, "o objetivismo é a luz-guia da razão reducionista, enquanto o relativismo é a recusa da existência de um ponto de Arquimedes universal (reducionista)" (idem, p. 21).

A metáfora da corda que esse autor utiliza para o pragmatismo volitivo, que sai fortalecido através da conjugação de cinco elementos, é fundamental para entender o modo como posteriormente vai analisar o caso da formulação da lei do tabaco nos EUA. Pretende, com essa corda, "entender as ações humanas tal como entender as instituições económicas que definem a escolha humana - os campos da ação individual e coletiva" (idem, p. 22). Essa corda, refere o autor, é composta por cinco tranças, digamos assim: (i) instituições económicas; (ii) políticas públicas; (iii) abdução; (iv) ação humana e (v) crença estabelecida. Nesse contexto, é a trança abdução que importa usar como referente. Esta dá-se quando "circunstâncias e eventos particulares são descobertos e nos encontramos na necessidade de uma explicação" (idem, p. 23). O propósito essencial da abdução é a produção de crença sobre eventos específicos (idem, p. 24). Esse pensamento, veremos, é crucial no caso da lei em análise neste texto. O silogismo abdutivo que Bromley propõe será, o modo mais eficaz de descobrir efetivamente as razões para um evento particular que sucedeu, no caso, a lei antitabaco nos EUA.

O fato surpreendente, C, é observado.

Mas se A fosse verdade, C justificar-se-ia.

Assim, há razão para suspeitar que A é verdade (ibid.).

Para aquele contexto, como para o português, o fato surpreendente, propõe, é a rápida mudança institucional. Assim, quais seriam as razões (ou seja, A) que poderiam justificar o fato surpreendente?

Nos EUA, como em Portugal, os fumantes, por volta da década de 1970, sabiam que o hábito de fumar poderia não ser seguro em termos de saúde futura, particularmente considerando a quantidade crescente de informação médica que provava existir algum tipo de relação direta e causal entre o consumo do tabaco (direta ou indiretamente) e doenças do foro pulmonar. Havia uma crença fundamentada. As provas científicas estavam assim a provocar uma mudança na percepção e crença por parte da população nos efeitos nocivos daquela substância. Em Portugal, o primeiro período onde se denota alguma preocupação com os efeitos do fumo do tabaco está refletido nas primeiras medidas "legislativas referentes à prevenção do tabagismo no país, primeiro no âmbito dos espetáculos, com a proibição de fumar dentro de recintos fechados onde se realizem espetáculos, seguida pelos diplomas relativos aos transportes públicos e aos desportos" (Portugal 2011) ${ }^{16}$. 
${ }^{16}$ Nessa referência pode-se igualmente consultar um historial resumido da relação entre o Estado português e a tabagismo. OMS sobre o tema do

Naquele momento, em ambos os países fumar poderia ser considerado um sinal de status social, e era crença generalizada de que fumar era algo que deveria ser feito, a bem da transmissão de um certo sinal exterior para a sociedade. Era um período onde não se questionava a presença do fumo do cigarro em um local público por um não fumante. Todavia, quando começaram a surgir provas científicas da relação entre o fumo e as doenças pulmonares, as pessoas não-fumantes começaram a questionar o porquê de terem que inalar o fumo não desejado de outras que o faziam. A norma, o habitus, começou a modificar-se. Particularmente porque começava a ser provado que os fumantes passivos sofriam igualmente pela inalação. Deixou então de ser algo meramente incomodativo para ser algo a que os não-fumantes reivindicavam o direito a não ser expostos. A nova informação (decorrente do novo conhecimento científico) foi portanto o que desencadeou "algo mais" na altercação entre fumantes e não-fumantes. É até esse momento que o trajeto entre os dois contextos é comum, e é a partir daqui que começam a divergir.

Bromley (2006) refere que, no caso estadunidense, houve vários processos judiciais interpostos por familiares de fumantes de longa data que acabaram por morrer vítimas de câncer do pulmão ou da garganta. Nessa época, ao argumento de que os fumantes eram-no de livre vontade, surgiram provas de que isso não era necessariamente verdade, pois as tabaqueiras tinham investido bastante dinheiro em produzir um tabaco que impossibilitasse progressivamente os fumantes de abandonar o seu vício. Este terá sido o derradeiro argumento que desencadeou reivindicações mais consistentes por parte dos não-fumantes pelo seu direito a não ser expostos ao fumo. Para este autor, "C" não foi afinal a rápida mudança institucional, mas essa revelação da constituição dos cigarros, um conhecimento científico que forneceu mais fundamentos para a anulação ou divisão dos espaços dedicados ao consumo de tabaco.

No contexto português, é crível que, apesar da ausência de mobilização judicial relativamente a consumidores de tabaco ou seus familiares (são desconhecidos casos que se reportem a essa temática), e de processos concernentes a provas que incriminassem as tabaqueiras de vender um vício e não um produto, o Estado tenha sido realmente o único responsável pela mudança institucional. É verdade que a crença relativamente ao tabaco é atualmente substancialmente diferente daquela que era há três décadas atrás, muito por causa do conhecimento científico. Como Fleck indicava, quando o conhecimento científico "é transformado em conhecimento vademecum pode moldar a opinião pública bem como a Weltanschaauung" e é nesta forma que vai posteriormente ser apropriado (Fleck apud Löwy 1988, p. 146).

Terá sido esse conhecimento (e a crença nele por parte dos indivíduos), conjuntamente com o contexto institucional supranacional existente, que terá levado a uma nova arquitetura institucional, culminando em uma nova política pública sobre o consumo do tabaco, não passando Portugal pela terceira fase do processo de mudança institucional que Bromley propõe.

\section{V - Conclusão}

O pragmatismo volitivo e a epistemologia por ele advogada fornecem ferramentas metodológicas e conceptuais úteis para a análise de fenómenos económicos que não podem ser examinados tomando o mercado ou a racionalidade dos indivíduos como únicos referenciais, como no modelo mecanicista paretiano, que indica aquilo que é "socialmente preferido" (Bromley 2006, p. 216), particularmente porque aquilo que é o "social" tem diferentes sentidos e apropriações. No caso das políticas públicas, a lei antitabaco é um óptimo exemplo, dada a rapidez e extensão da sua aplicação. Através do recurso aos conceitos de um enquadramento teórico restrito da economia institucional, 
procurou-se uma caraterização breve dos mesmos, mas aferindo simultaneamente da sua aplicabilidade em um caso que possui o mesmo princípio, em dois países. Refira-se que essa é, aliás, uma das mais-valias do pragmatismo volitivo: é defensor de um relativismo que assente à multiplicidade de racionalidades e cognições, de culturas e enquadramentos institucionais. Essa será, certamente, uma das razões pelas quais se considera esse modo de pensar as instituições plausível de render trabalhos científicos na área da saúde e pela qual foi selecionado para o presente texto. Precisamente porque, no caso da lei antitabaco, admite que um mesmo arranjo institucional final possa ter percursos diferentes (como por exemplo a mobilização no ramo judicial sobre o tabaco que se deu num país e foi ausente no outro), mas culminando em um mesmo resultado. Pois foi a vontade humana em ação, a olhar para o futuro, que levou ao novo desenho institucional em ambos os contextos. Tal deveu-se ao momento em que houve um novo conhecimento, surgido em determinado momento, que veio desestabilizar crenças enraizadas, tornando uma fonte de incerteza o arranjo institucional existente. E é isso o pragmatismo volitivo, uma preocupação com as maneiras como a vontade humana olha para os desdobramentos possíveis de um futuro vindouro, face a novos eventos, como descobertas científicas, tentando articular as razões que uns e outros defendem, e que levem a diferentes fins, todos eles plausíveis. Porque só a crença que aquela política, naquele momento, poderia levar àquele resultado desejado. Afinal de contas, "uma crença é uma rampa de lançamento para a ação" (ibid.). E essa constituiu razão suficiente para que o processo tivesse início.

\footnotetext{
"Quando entendermos a natureza e propósito das instituições, e quando entendermos que diferentes instituições são a razão para resultados diferentes, estaremos perto da formulação de uma teoria das instituições económicas e da mudança institucional" (idem, p. 27).
}

Carlos Barradas (barradascarlos@ces.uc.pt) é Doutorando no programa "Governação, Conhecimento e Inovação", da Universidade de Coimbra (Portugal), em cotutela com o programa "Direitos Humanos, Saúde Global e Política da Vida", da Fundação Oswaldo Cruz (Brasil).

\section{Referências}

Bromley, D.W. 2006. Sufficient Reason: Volitional pragmatism and the meaning of economic institutions. Princeton: Princeton University Press.

Câncio, F. 2007. A minha veia e os pulmões dos outros. Diário de Notícias, 4 maio. Disponível em: http://www.dn.pt/inicio/interior.aspx?content_id = 656924. Acesso em: 21 ago 2014 .

Commons, J.R. 1931. Institutional Economics. American Economic Review, 21, pp. 648-657.

Duarte, M. 2011. Movimentos na Justiça: o direito e o movimento ambientalista em Portugal. Coimbra: Almedina.

Fleck, L. 1986. Scientific Observation and Perception in General. In: R.S. Cohen; T. Schnelle, eds. Cognition and Fact: Materials on Ludwik Fleck. Dordrecht: Reidel.

Good, B. 1994. Medicine, Rationality and Experience: An anthropological perspective. Cambridge, UK: Cambridge University Press.

Hodgson, G.M. 2006. What Are Institutions? Journal of Economic Issues, 40(1), pp. 1-25. 2009. Institutional Economics into the Twenty-First Century. Studi e Note di Economia, 14(1), pp. 3-26.

Löwy, I. 1988. Ludwik Fleck on the Social Construction of Medical Knowledge. Sociology of Health \& Illness, 10(2), pp. $133-155$.

Reis, J. 2009. Ensaios de economia impura. Coimbra: Almedina.

Samuels, W.J. 1989. Some Fundamentals of the Economic Role of Government. Journal of Economic Issues, 23(2), pp. 427-433.

Santos, B.S. 2003. Poderá o direito ser emancipatório? Revista Crítica de Ciências Sociais, 65, pp. 3-76.

Tavares, J.M. 2007. Cale-me a criancinha que não consigo mastigar. Diário de Notícias, 8 maio. Disponível em http://www.dn.pt/inicio/interior.aspx?content_id = 657214. Acesso em 21 ago 2014 . 2008. 2008: ano do terror. Jornal Expresso, 7 jan. Disponível em: http://expresso.sapo.pt/2008-ano-do-terror=f207958. Acesso em: 5 set 2014.

Valente, V. P. 2006. A heresia. Jornal Público, 9 Abr. 


\title{
Outras fontes
}

Portugal. 2011. Mostra documental. Prevenção e controlo do tabagismo. Instituto Nacional de Saúde. Disponível em: http://www.insa.pt/sites/INSA/Portugues/ComInf/Noticias/Paginas/MostraDocumentalTabagismo.aspx. Acesso em: 21 ago 2014.

\begin{abstract}
Using a variety of empirical sources and a specific theoretical framework, this article attempts to assess the combination of actors and moments that triggered a new "constellation of institutions in the legislative, executive and judicial branches" and led to the implementation of a regulatory structure for the tobacco sale and consumption in Portugal, thus changing the discourse on rights and duties of individuals and, ultimately, habits and beliefs rooted in social life. The research was conducted using a variety of legislative and media materials with the focus on the anti-tobacco law in Portugal. The initial question was to assess how the new institutional economics and volitional pragmatism constitute adequate theoretical and methodological tools for the analysis and interpretation of the development and establishment of the anti-tobacco law in Portugal. The new institutionalism, the volitional pragmatism and the epistemology it advocates provide useful conceptual and methodological tools for the analysis of economic phenomena that can not be examined by taking the market or individual's rationality as unique references, in a mechanistic model like the Paretian, which indicates what is "socially preferred", particularly because what is "social" has different meanings and appropriations. In the case of public policy, the anti-tobacco law is a great example, given the swiftness and extent of its application. Making use of and briefly describing the main concepts deriving from a restricted theoretical framework of institutional economics, its applicability to other empirical contexts was sought. This article attributes further consistency to the non-dominant theoretical models based on institutional economics that satisfactorily explain the emergence of anti-tobacco laws and provokes new research leading to the consolidation and validity of a non-dominant theoretical and methodological standpoint. Finally, it is needed to say that such theoretical and methodological models contain explanatory capacity, motivated by its application in another empirical context.
\end{abstract}

KEYWORDS: tobacco law; institutional economics; public policy; government; volitional pragmatism. 